\title{
Usefulness of Postnatal Echocardiograms in Patients with Omphaloceles Who Previously Had a Normal Fetal Echocardiogram
}

\author{
Michael Clark · Jennifer H. Aldrink - Bernadette Richards • \\ Rebecca Corbitt · Corey Stiver · Clifford L. Cua (D)
}

Received: August 30, 2021 / Published online: October 30, 2021

(c) The Author(s) 2021

\begin{abstract}
Introduction: Neonates with omphaloceles routinely have a transthoracic echocardiogram (TTE) performed due to a high association with congenital heart defects (CHD). The utility of a TTE in these patients with a normal fetal echocardiogram is unknown. The primary objective of this study was to determine whether a critical CHD diagnosis was missed in patients with an omphalocele who had a normal fetal echocardiogram. The secondary objective of the study was to determine whether any CHD diagnosis was missed postnatally when a fetal echocardiogram was read as normal.

Methods: A retrospective chart review was performed of patients with omphaloceles born between January 1, 2008, and June 30, 2020. Patients were included if they had a fetal echocardiogram that was read as normal and had a postnatal echocardiogram performed. Baseline demographics, postnatal data echocardiographic findings, and hospital course were collected. Critical CHD was defined as CHD requiring neonatal cardiac intervention.
\end{abstract}

M. Clark · J. H. Aldrink - B. Richards - R. Corbitt C. Stiver · C. L. Cua ( $₫)$

Nationwide Children's Hospital, Columbus, $\mathrm{OH}$ 43205, USA

e-mail: clcua@hotmail.com
Results: Fifty-six fetal echocardiograms on patients with omphaloceles were performed, of which 24 patients met the inclusion criteria. No patient was diagnosed with a critical CHD postnatally (negative predictive value $[\mathrm{NPV}]=$ $100 \%)$. Two patients were diagnosed with ventricular septal defects (VSD) postnatally $(\mathrm{NPV}=91.7 \%)$. One of the VSDs required closure with a patch at 4 months of life, while the other, a small muscular VSD, closed spontaneously within the first year of life. Both patients had a murmur on exam during their initial hospital stay. The patient that required surgery also had an abnormal electrocardiogram and chest X-ray. There were no mortalities due to cardiac causes in these patients.

Conclusion: Critical CHD was not missed on any patient with an omphalocele who had a normal fetal echocardiogram. All other patients with omphaloceles who had CHD diagnosed postnatally had an abnormal clinical finding on postnatal evaluation. The routine performance of a postnatal TTE in patients with an omphalocele who had a normal fetal echocardiogram may not be needed in those with a normal clinical workup. Further studies evaluating echocardiographic imaging recommendations are needed to maximize care and optimize resource allocation in this complex patient population.

Keywords: $\quad$ Omphalocele; $\quad$ Fetal echocardiography; Neonatology 


\section{Key Summary Points}

Guidelines recommend a fetal echocardiogram in fetuses with an omphalocele because of the increased incidence of congenital heart disease in this population.

In this study, no critical congenital heart disease was missed on fetal echocardiography in patients with an omphalocele.

The need for a routine postnatal echocardiogram on patients with an omphalocele who had a normal fetal echocardiogram may not necessarily be needed in those with a normal clinical workup.

\section{INTRODUCTION}

The incidence of omphaloceles has been estimated to be 1 per 4000-7000 live births [1-3]. Patients with omphaloceles frequently have other associated congenital abnormalities that may affect their overall morbidity and mortality $[4,5]$. Congenital heart disease (CHD) is one abnormality that is frequently associated with this patient population [4, 6-9]. Diagnosing significant CHD is essential for the care of these patients. In most centers, it is routine to obtain a screening echocardiogram postnatally in this population prior to any intervention on the omphalocele.

The American Heart Association states that it is a class I recommendation to perform a fetal echocardiogram in fetuses when extracardiac abnormalities are present [10]. This recommendation encompasses gastrointestinal abnormalities because of the association with CHD in this population. Appropriate use criteria for performing an initial echocardiogram in an outpatient pediatric cardiology setting also exist, but these recommendations do not necessarily consider whether the patient previously had a normal fetal echocardiogram [11]. The need for a postnatal echocardiogram in patients with omphaloceles that previously had a normal fetal echocardiogram is unknown.

The primary goal of this study was to determine whether the diagnosis of a complex CHD was missed in patients with an omphalocele who had a fetal echocardiogram that was previously read as normal. The secondary goal of the study was to determine whether any CHD was missed postnatally when a fetal echocardiogram was read as normal.

\section{METHODS}

This retrospective study was approved by the Institutional Review Board at Nationwide Children's Hospital, and all ethical standards were followed for research purposes. Waiver of HIPAA authorization and alteration of the consent process was granted. This study was performed in accordance with the Helsinki Declaration of 1964 and its later amendments.

The Nationwide Children's Hospital database was searched for all patients with the diagnosis of an omphalocele who had a date of birth during the period from January 1, 2008, through June 30, 2020. The International Classification of Diseases Ninth and Tenth Edition diagnostic codes were used for identification purposes, 756.72 and Q79.2, respectively.

Patients were included if they had the diagnosis of an omphalocele and had both a fetal echocardiogram that was read as normal and had a postnatal echocardiogram performed. Patients were excluded if they did not have a diagnosis of omphalocele; if they had a diagnosis of omphalocele, but did not have a fetal echocardiogram performed; if they had a fetal echocardiogram performed and there was concern for CHD; or if there was no postnatal echocardiogram performed.

Complex CHD was defined as a risk adjustment for surgery for congenital heart disease category (RACHS) $\geq 3$ CHD $[12,13]$. The RACHS system divides CHD into six tiers based on the CHD complexity of the lesion and expected outcomes: the higher the tier, the more complex the CHD. RACHS $\geq 3$ was used 
as a cutoff point because this would encompass the more complex CHD lesions. All other CHD diagnoses were also recorded. Patent foramen ovale and patent ductus arteriosus were not considered pathologic CHD.

Patients included in the study had their fetal echocardiogram and postnatal echocardiogram reviewed to determine whether there were discrepancies between the two reports. Age at the initial fetal and postnatal echocardiogram was recorded. The last set of vital sign measurements, physical exam findings, and/or diagnostic tests prior to the initial echocardiogram were also documented. Any interventional cardiac procedures, defined as catheterization or surgical, were recorded for any patient noted to have CHD. The overall outcome for any patient diagnosed with a CHD was also detailed.

All data are presented as means and standard deviations unless otherwise stated. The negative predictive value of a normal fetal echocardiogram was calculated.

\section{RESULTS}

During this time period, a total of 110 patients were diagnosed with an omphalocele postnatally. Fifty-six of these patients had a fetal echocardiogram performed. Thirty-two patients were excluded, 28 because of concerns of CHD (ventricular septal defect: $n=19$; , atrioventricular septal defect: $n=3$, double outlet right ventricle: $n=2$, dextrocardia: $n=1$, pulmonary stenosis: $n=1$, hypoplastic left heart: $n=1$, ectopia cordis: $n=1$ ), and four because of missing records. This study therefore consisted of 24 patients with an omphalocele and who had a fetal echocardiogram that was reported as normal and also had a postnatal echocardiogram performed.

In the 24 patients that met the inclusion criteria, the gestational age at the time of the fetal echocardiogram was $22.8 \pm 3.7$ weeks. Postnatal echocardiogram was performed at $1.4 \pm 2.7$ days, median 0 days (0-10 days). Clinical data are presented in Table 1 . No patient was diagnosed with a RACHS $\geq 3$ category $\mathrm{CHD}$. The negative predictive value for a normal fetal echocardiogram to rule out a
RACHS $\geq 3$ category CHD was thus $100 \%$. Two patients were noted to have ventricular septal defects; thus, the negative predictive value with a normal fetal echocardiogram for any CHD in a patient was $91.7 \%(22 / 24)$. Upon reevaluation of these two patients' fetal echocardiograms after the postnatal diagnosis, a diagnosis of CHD on the fetal echocardiograms still could not be definitively determined.

One patient had a trivial to small muscular ventricular septal defect. This defect was followed conservatively and self-resolved by 1 year of age with no intervention required. Another patient had a moderate perimembranous ventricular septal defect that was surgically closed at 4 months of age. Both patients had a murmur noted on physical exam. The latter patient also had an abnormal electrocardiogram (EKG) with biventricular hypertrophy and strain pattern noted. Incidentally, another patient was postnatally diagnosed with Williams syndrome. This patient's initial postnatal echocardiogram did not indicate supravalvular aortic stenosis, but on regular outpatient follow-up, supravalvular stenosis subsequently developed.

\section{DISCUSSION}

Patients with omphaloceles are known to have an increased risk for CHD [4, 6-8]. Therefore, fetal echocardiograms are recommended for fetuses with omphaloceles [10], and postnatal echocardiograms are routinely obtained regardless of whether a normal fetal echocardiogram was reported. The utility of a postnatal echocardiogram in this situation is unknown. In this study, no patient had a RACHS $\geq 3$ category CHD. There were some missed CHD that were detected with a postnatal echocardiogram, but these patients had a murmur and/or an abnormal EKG that would suggest that further testing should be performed [11].

The fact that no RACHS $\geq 3$ category CHD was missed on the fetal echocardiogram in this high risk population is reassuring. This is consistent with previous studies showing that the sensitivity for fetal echocardiograms to detect complex CHD is, in general, greater than $80 \%$ [14-18]. These findings are also consistent with 
Table 1 Clinical data

Maternal complications

Mode of delivery

Gestational age (weeks)

Birth weight $(\mathrm{kg})$

Gender (male:female)

Genetic syndromes

Giant omphalocele

Length of hospitalization (days)

$$
\begin{aligned}
& n=2, \text { pre-eclampsia } \\
& n=2, \text { chronic hypertension } \\
& n=1, \text { gestational diabetes } \\
& n=1, \text { hypothyroidism } \\
& n=1, \text { factor V Leiden deficiency } \\
& n=17, \text { C-section } \\
& n=5, \text { vaginal delivery } \\
& n=2, \text { missing data } \\
& 36.2 \pm 3.01 \\
& 3.1 \pm 0.8 \\
& 11: 13 \\
& n=5, \text { Beckwith-Wiedemann } \\
& n=1, \text { Williams } \\
& n=1, \text { Moebius } \\
& n=1, \text { Milroy } \\
& n=1,9 \text { deletion }
\end{aligned}
$$

8

Median 45 (7-224) other studies showing that more complex CHD are more likely to be detected prenatally than less complex CHD when complete fetal echocardiograms are performed $[19,20]$. This data supports the view that in the vast majority of cases, complex CHD will not be missed when complete fetal echocardiograms are performed in this population.

Despite the fact that RACHS $\geq 3$ category CHD was not missed, there still remained patients that were diagnosed with CHD in the postnatal period. As noted above, fetal echocardiograms do not have a $100 \%$ sensitivity in detecting all CHD. The sensitivity for fetal echocardiograms may range as low as $20 \%$ to as high as $80 \%$ for revealing minor CHD [14-17]. One recent study evaluating 17,096 fetal echocardiograms noted that diagnostic discrepancies between the fetal and the postnatal echocardiogram occurred $13.5 \%$ of the time, with discrepancies most often involving the ventricular septum (23\%) [21]. This is consistent with this study, where both missed defects involved the ventricular septum.

Both patients that had a missed CHD diagnosis were noted to have a murmur on physical exam. One study noted that physical exam and chest X-ray evaluation of patients with esophageal atresia, omphalocele, or anorectal malformations had sensitivity, specificity, positive predictive value, and negative predictive value of detecting major CHD of 100\%, 64\%, $28 \%$, and $100 \%$, respectively. Additionally, the sensitivity, specificity, positive predictive value, and negative predictive value of detecting both major and minor CHD was $63 \%, 69 \%, 58 \%$, and $73 \%$, respectively [22]. That study concluded that "routine echocardiography before embarking on surgical intervention may not always be necessary but should be reserved for infants 
with abnormal clinical and/or radiologic findings."

The class I recommendation to perform a fetal echocardiogram on fetuses with known extracardiac abnormalities is clearly warranted [10]. However, the utility in performing screening echocardiograms in patients with omphaloceles even if a fetal echocardiogram with a normal report exists is less clear. Appropriate use criteria (AUC) exist for the initial use of an echocardiogram in the pediatric population [11]. The AUC state that it is appropriate to perform a postnatal echocardiogram if there was an abnormality on the fetal echocardiogram, but it clearly states that it is rarely appropriate to obtain an echocardiogram if a "previously normal echocardiogram with no change in cardiovascular status or family history" exists. The AUC also state that it is appropriate to obtain an echocardiogram in patients with "clinically suspected syndrome or extracardiac congenital anomaly known to be associated with congenital heart disease," but it does not necessarily consider whether a fetal echocardiogram with a normal report was performed. The question then arises whether a fetal echocardiogram is equivalent to a postnatal echocardiogram in quality. There are obvious defects that are difficult or impossible to diagnose on the fetal echocardiogram, such as a patent ductus arteriosus, coarctation of aorta, and septal defects; thus, a fetal echocardiogram is not equivalent to a postnatal echocardiogram. Also, a fetal echocardiogram cannot necessarily predict postnatal physiology. Some patients with omphaloceles have been noted to have increased pulmonary vasculature resistance after birth [23-26]. Nevertheless, the AUC take into account these possible shortcomings of the fetal echocardiogram by noting that it is appropriate to obtain an echocardiogram if any of the following are present: a normal murmur is present, but there are signs of cardiovascular disease; pathologic murmur; signs and symptoms of congestive heart failure; central cyanosis; abnormal chest X-ray suggestive of cardiovascular disease; abnormal EKG; desaturation based on pulse oximetry; or previous normal echocardiogram with a change in cardiovascular status or family history [11]. In these cases, a postnatal echocardiogram is not only appropriate, but necessary, to aid in patient management.

The patients with omphaloceles in this study that had a missed CHD diagnosis on the fetal echocardiogram would still have had an echocardiogram by the AUC stated above. By using AUC both pre- and postnatally, unnecessary testing could be avoided, while still not compromising patient care. Assuming that there were no cardiac concerns in the newborn nursery on a neonate with an omphalocele that had a reported normal fetal echocardiogram, an alternative algorithm could be to refer this patient for a pediatric cardiology visit for further evaluation, and the use of AUC could be implemented.

There are multiple limitations of this study. This was a retrospective study with all the inherent shortcomings of such a design. The study assessed a single-center experience, and the overall numbers were thus small despite evaluating a 12-year time span. It was sometimes difficult to impossible to determine from the clinical notes whether the murmur heard was thought to be pathologic or not. To prevent any subjective bias, all murmurs were considered pathologic unless the note clearly stated a normal murmur. This assumption may not be totally accurate. Considering the population being evaluated, we felt that, practically speaking, there would have been a low threshold for obtaining an echocardiogram if a murmur was heard. The sensitivity and specificity of the fetal echocardiogram for the diagnosis of CHD in patients with omphaloceles was not calculated, but that was not the goal of this study. The sensitivity or specificity of fetal echocardiography has been previously reported in the general population [14-18]. Due to the possible torsion of the abdominal contents, it is possible that CHD such as inferior vena cava abnormalities may be more easily missed in this population [27], but we did not necessarily find that in this study. 


\section{CONCLUSION}

RACHS $\geq 3$ category CHD was not missed on any fetal echocardiograms performed on patients with omphaloceles. All the other patients that had CHD diagnosed postnatally had an abnormal finding on evaluation. Further studies testing these various recommendations with prospective data and a larger sample size are warranted to maximize care in this patient population.

\section{ACKNOWLEDGEMENTS}

Compliance with Ethics Guidelines. This retrospective study (00001455) was approved by the Institutional Review Board at Nationwide Children's Hospital and all ethical standards were followed for research purposes. Waiver of HIPAA authorization and alteration of the consent process was granted. This study was performed in accordance with the Helsinki Declaration of 1964 and its later amendments.

Funding. No funding or sponsorship was received for this study or publication of this article.

Authorship. All named authors meet the International Committee of Medical Journal Editors (ICMJE) criteria for authorship for this article, take responsibility for the integrity of the work as a whole, and have given their approval for this version to be published.

Author Contributions. Concept and Design: MC, CC. Statistical Analysis: MC, CC. Drafting: MC, JA. Review: MC, JA, BR, RC, CS, CC.

Disclosures. Michael Clark, Jennifer H Aldrink, Bernadette Richards, Rebecca Corbitt, Corey Stiver, and Clifford L Cua have nothing to disclose.

Data Availability. The datasets generated during and/or analyzed during the current study are available from the corresponding author on reasonable request.
Open Access. This article is licensed under a Creative Commons Attribution-NonCommercial 4.0 International License, which permits any non-commercial use, sharing, adaptation, distribution and reproduction in any medium or format, as long as you give appropriate credit to the original author(s) and the source, provide a link to the Creative Commons licence, and indicate if changes were made. The images or other third party material in this article are included in the article's Creative Commons licence, unless indicated otherwise in a credit line to the material. If material is not included in the article's Creative Commons licence and your intended use is not permitted by statutory regulation or exceeds the permitted use, you will need to obtain permission directly from the copyright holder. To view a copy of this licence, visit http:// creativecommons.org/licenses/by-nc/4.0/.

\section{REFERENCES}

1. Stallings EB, Isenburg JL, Short TD, et al. Population-based birth defects data in the United States, 2012-2016: a focus on abdominal wall defects. Birth Defects Res. 2019;111:1436-47.

2. Mai CT, Isenburg J, Langlois PH, et al. Populationbased birth defects data in the United States, 2008 to 2012: presentation of state-specific data and descriptive brief on variability of prevalence. Birth Defects Res A. 2015;103:972-93.

3. Springett A, Draper ES, Rankin J, et al. Birth prevalence and survival of exomphalos in England and Wales: 2005 to 2011. Birth Defects Res A. 2014;100: 721-5.

4. Stoll C, Alembik Y, Dott B, Roth MP. Omphalocele and gastroschisis and associated malformations. Am J Med Genet A. 2008;146A:1280-5.

5. Abbasi N, Moore A, Chiu P, et al. Prenatally diagnosed omphaloceles: report of 92 cases and association with Beckwith-Wiedemann syndrome. Prenat Diagn. 2021;41:798-816.

6. Tulloh RM, Tansey SP, Parashar K, De Giovanni JV, Wright JG, Silove ED. Echocardiographic screening in neonates undergoing surgery for selected gastrointestinal malformations. Arch Dis Child Fetal Neonatal Ed. 1994;70:F206-8. 
7. Greenwood RD, Rosenthal A, Parisi L, Fyler DC, Nadas AS. Extracardiac abnormalities in infants with congenital heart disease. Pediatrics. 1975;55: 485-92.

8. Gallo P, Nardi F, Marinozzi V. Congenital extracardial malformations accompanying congenital heart disease. G Ital Cardiol. 1976;6:450-9.

9. Wallgren EI, Landtman B, Rapola J. Extracardiac malformations associated with congenital heart disease. Eur J Cardiol. 1978;7:15-24.

10. Donofrio MT, Moon-Grady AJ, Hornberger LK, et al. Diagnosis and treatment of fetal cardiac disease: a scientific statement from the American Heart Association. Circulation. 2014;129:2183-242.

11. Campbell RM, Douglas PS, Eidem BW, Lai WW, Lopez L, Sachdeva R. ACC/AAP/AHA/ASE/HRS/ SCAI/SCCT/SCMR/SOPE 2014 appropriate use criteria for initial transthoracic echocardiography in outpatient pediatric cardiology: a report of the American College of Cardiology Appropriate Use Criteria Task Force, American Academy of Pediatrics, American Heart Association, American Society of Echocardiography, Heart Rhythm Society, Society for Cardiovascular Angiography and Interventions, Society of Cardiovascular Computed Tomography, Society for Cardiovascular Magnetic Resonance, and Society of Pediatric Echocardiography. J Am Coll Cardiol. 2014;64:2039-60.

12. Jenkins KJ, Gauvreau K, Newburger JW, Spray TL, Moller JH, Iezzoni LI. Consensus-based method for risk adjustment for surgery for congenital heart disease. J Thorac Cardiovasc Surg. 2002;123:110-8.

13. Jenkins KJ, Gauvreau K. Center-specific differences in mortality: preliminary analyses using the Risk Adjustment in Congenital Heart Surgery (RACHS-1) method. J Thorac Cardiovasc Surg. 2002;124: 97-104.

14. Achiron R, Glaser J, Gelernter I, Hegesh J, Yagel S. Extended fetal echocardiographic examination for detecting cardiac malformations in low risk pregnancies. BMJ. 1992;304:671-4.

15. Anandakumar C, Nuruddin Badruddin M, Chua TM, Wong YC, Chia D. First-trimester prenatal diagnosis of omphalocele using three-dimensional ultrasonography. Ultrasound Obstet Gynecol. 2002;20:635-6.

16. Hafner E, Scholler J, Schuchter K, Sterniste W, Philipp K. Detection of fetal congenital heart disease in a low-risk population. Prenat Diagn. 1998;18: 808-15.

17. Rustico MA, Benettoni A, D'Ottavio G, et al. Fetal heart screening in low-risk pregnancies. Ultrasound Obstet Gynecol. 1995;6:313-9.

18. Stumpflen I, Stumpflen A, Wimmer M, Bernaschek G. Effect of detailed fetal echocardiography as part of routine prenatal ultrasonographic screening on detection of congenital heart disease. Lancet. 1996;348:854-7.

19. Quartermain MD, Pasquali SK, Hill KD, et al. Variation in prenatal diagnosis of congenital heart disease in infants. Pediatrics. 2015;136:e378-85.

20. Li Y, Hua Y, Fang J, et al. Performance of different scan protocols of fetal echocardiography in the diagnosis of fetal congenital heart disease: a systematic review and meta-analysis. PLoS ONE. 2013;8:e65484.

21. Mozumdar N, Rowland J, Pan S, et al. Diagnostic accuracy of fetal echocardiography in congenital heart disease. J Am Soc Echocardiogr. 2020;33: 1384-90.

22. Nasr A, McNamara PJ, Mertens L, et al. Is routine preoperative 2-dimensional echocardiography necessary for infants with esophageal atresia, omphalocele, or anorectal malformations? J Pediatr Surg. 2010;45:876-9.

23. Dal Col AK, Bhombal S, Tacy TA, Hintz SR, Feinstein J, Altit G. Comprehensive echocardiographic assessment of ventricular function and pulmonary pressure in the neonatal omphalocele population. Am J Perinatol. 2021;38:e109-15.

24. Baerg JE, Thorpe DL, Sharp NE, et al. Pulmonary hypertension predicts mortality in infants with omphalocele. J Neonatal-Perinat Med. 2015;8: 333-8.

25. Hutson S, Baerg J, Deming D, St Peter SD, Hopper A, Goff DA. High prevalence of pulmonary hypertension complicates the care of infants with omphalocele. Neonatology. 2017;112:281-6.

26. Partridge EA, Hanna BD, Panitch HB, et al. Pulmonary hypertension in giant omphalocele infants. J Pediatr Surg. 2014;49:1767-70.

27. Ayub SS, Taylor JA. Cardiac anomalies associated with omphalocele. Semin Pediatr Surg. 2019;28: 111-4. 